\title{
The design of a double-tuned two-port surface resonator and its application to in vivo Hydrogen- and Sodium-MRI
}

\section{Authors:}

Friedrich Wetterling ${ }^{1,2}$

Miroslav Högler ${ }^{3}$,

Ute Molkenthin ${ }^{3}$,

Sven Junge ${ }^{3}$,

Lindsay Gallagher ${ }^{4}$,

I. Mhairi Macrae ${ }^{4}$,

Andrew J. Fagan ${ }^{1,5}$

\section{Affiliation:}

${ }^{1}$ School of Physics, Trinity College Dublin, University of Dublin, Ireland

${ }^{2}$ Computer Assisted Clinical Medicine, University of Heidelberg, Mannheim, Germany

${ }^{3}$ Bruker BioSpin GmbH, Ettlingen, Germany

${ }^{4}$ Glasgow Experimental MRI Centre, Institute of Neuroscience and Psychology, College of Medicine, Veterinary and Life Sciences, University of Glasgow, United Kingdom.

${ }^{5}$ Centre for Advanced Medical Imaging, St. James’s Hospital /Trinity College Dublin, Ireland

\section{Abbreviated Title:}

Two-Port ${ }^{23} \mathrm{Na} /{ }^{1} \mathrm{H}$ Surface Resonator

\section{Corresponding Author:}

Friedrich Wetterling, Theodor-Kutzer Ufer 3-5, 68163 Mannheim

Email: wetterlf@tcd.ie $\quad$ Tel: (+353) 85-7227-301

\section{Grant funding:}

Science Foundation Ireland grant number "06/RFP/PHY006" 


\begin{abstract}
The design and construction of a two-port surface transceiver resonator for both ${ }^{1} \mathrm{H}$ - and ${ }^{23} \mathrm{Na}-\mathrm{MRI}$ in the rodent brain at $7 \mathrm{~T}$ is described. Double-tuned resonators are required for accurately co-registering multi-nuclei data sets, especially when the time courses of ${ }^{1} \mathrm{H}$ and ${ }^{23} \mathrm{Na}$ signals are of interest as, for instance, when investigating the pathological progression of ischaemic stroke tissue in vivo. In the current study, a single-element two-port surface resonator was developed wherein both frequency components were measured with the same detector element but with each frequency signal routed along different output channels. This was achieved by using the null spot technique, allowing for optimal variable tuning and matching of each channel in situ within the MRI scanner. The ${ }^{23} \mathrm{Na}$ signal to noise ratio, measured in the ventricles of the rat brain, was increased by a factor of four compared to recent state-of-the-art rat brain studies reported in the literature. The resonator's performance was demonstrated in an in vivo rodent stroke model, where regional variations in ${ }^{1} \mathrm{H}$ apparent diffusion coefficient maps and the ${ }^{23} \mathrm{Na}$ signal were recorded in an interleaved fashion as a function of time in the acute phase of the stroke without having to exchange, re-adjust, or re-connect resonators between scans. Using the practical construction steps described in this paper, this coil design.
\end{abstract}

Keywords: ${ }^{23}$ Na-MRI, Double-Tuning, Two-Port Surface Resonator, coil construction

Abbreviations: TSC - tissue sodium concentration, rf - radiofrequency, SNR - signal-tonoise-ratio 


\section{INTRODUCTION}

With increasing static magnetic field strengths and stronger, faster and more accurately controllable gradient and acquisition hardware, ${ }^{23} \mathrm{Na}$ Magnetic Resonance Imaging $\left({ }^{23} \mathrm{Na}-\mathrm{MRI}\right)$ has become a promising technique to investigate diseased tissue states non-invasively in pre-clinical models of disease [1-4]. The potential diagnostic benefits of ${ }^{23} \mathrm{Na}-\mathrm{MR}$ imaging have recently been demonstrated for common pathological conditions such as tumor [5, 6], stroke [7-9], Alzheimer disease [10], paramyotonia [11], arthritis [12], multiple sclerosis [13] and functional renal imaging [14] in humans. In addition, pre-clinical in vivo ${ }^{23} \mathrm{Na}$ MRI enables one to temporally follow pathological progression in animal models of common human disease [14-16].

However, ${ }^{23} \mathrm{Na}-\mathrm{MRI}$ generally suffers from low Signal-to-Noise-Ratios (SNR) primarily due to the low $45 \mathrm{mM}^{23} \mathrm{Na}$ concentration in tissue (equivalent to a $0.3 \% \mathrm{NaCl}$ solution) [17]. Imaging of the rat brain poses an additional challenge, due to the small voxel sizes typically required (in the $\mu$ range) to achieve the spatial resolution necessary to identify common brain structures such as the cortex and the subcortex in rodent stroke models. As a result, deriving a meaningful conclusion from such low resolution data in recently published studies has proved difficult $[1,18,19]$. Attempts have been made to improve the achievable SNR in ${ }^{23} \mathrm{Na}-\mathrm{MRI}$ by developing optimal radiofrequency resonators [20], although it is clear that higher spatial-temporal resolution is required if ${ }^{23} \mathrm{Na}-\mathrm{MRI}$ is to realize its considerable potential in in vivo studies.

Dual resonator systems consisting of separate volume transmit resonators and receive-only surface detectors combine the benefits of a homogeneous $\mathrm{B}_{1}$-transmit field and good receiver sensitivity [16]; however, despite geometric and active decoupling possibilities the sensitivity of such configurations for in vivo MRI invariably suffer compared to surface transceiver coils due to the close proximity of the surface detector to the volume transmitter. If $\mathrm{B}_{1}$-field homogeneity is not critical, superior sensitivity can be achieved with transceiver surface coils.

When designing a surface resonator for ${ }^{23} \mathrm{Na}-\mathrm{MRI}$, it is furthermore important to include ${ }^{1} \mathrm{H}$ imaging capabilities to allow for co-registration of the lower-resolution ${ }^{23} \mathrm{Na}$ images with ${ }^{1} \mathrm{H}$ anatomical data. For applications such as acute stroke imaging, for instance, such double-tuning allows for a comparison of the temporal evolution of the ${ }^{23} \mathrm{Na}$ 
signal with concomitant signal changes in diffusion- and also $\mathrm{T}_{2}$-weighted ${ }^{1} \mathrm{H}-\mathrm{MR}$ data without the need to reposition the sample. Ideally, a resonator with two separate ports and the option to separately tune and match both channels is required. The challenge in this case stems from the need to achieve sufficient independence of both channels, for example in separating each channel's connection port in order to obtain two independently tune- and match-able resonance modes. In this way, the sensitivity for both channels could in theory be optimized, ideally without disturbing the system when switching between ${ }^{23} \mathrm{Na}$ and ${ }^{1} \mathrm{H}$ imaging during the course of a long multi-modal MRI experiment.

A number of distinct approaches to the design of double-tuned resonators have been described in the literature. The first approach is based on the use of two geometrically decoupled resonators, with each resonating at a specific frequency corresponding to the nuclei of interest such that the temporal magnetic flux generated by one resonator through the other is near zero [21]. A limitation of this approach arises in the case of surface resonators, which must be centred above the rat brain in order to achieve their optimal sensitivity; however, the geometrically decoupling of two such resonators will invariably result in one or both being sub-optimally located with respect to the rat brain. Hence, this approach is predominantly employed for volume resonators such as birdcage coils, where the two resonant modes can be easily arranged orthogonally to each other on the resonator's cylindrical structure without changing their sensitivity range [21, 22].

The second approach, the transformer-coupled design [23], achieves the double-tuned state through two physically separated, but strongly coupled resonance structures, which are both tuned to the same resonance frequency [24] or each to one of the target frequencies [20] prior to resonator coupling. In the latter case, blocking circuits [20] are required to limit the lower resonance mode to only a single resonator and to create two ports for the measurement of the two separate frequency signals. An inductively-coupled ${ }^{31} \mathrm{P} /{ }^{1} \mathrm{H}$ surface coil was designed using this principle [24], however, the connection of two coaxial cables without interference on the higher frequency channel is extremely difficult using this resonator design, which invariably lowers the achievable SNR. Furthermore, as with the previous approach, the ${ }^{1} \mathrm{H}$ and ${ }^{23} \mathrm{Na}$ channels are difficult to be adjusted without interfering with the other channel's tuning and matching parameters, which ultimately restricts one's ability to switch quickly between nuclei during an MRI experiment without having to readjust the resonance circuit or trade-off sensitivity in one of the two channels. 
A third design approach achieves the double-tuned state via the insertion of a second resonant circuit (a "trap" circuit) into the original resonance loop. The trap consists of a parallel LC network formed using a passive inductor [25], the use of which invariably degrades the sensitivity since it contributes to noise generation and not to MR signal pick-up. On the other hand, this approach requires only one resonance structure for both frequencies, which simplifies the MR adjustments using the high sensitivity ${ }^{1} \mathrm{H}$ channel and allows for the optimum positioning of the sample relative to the resonance structure. Due to the identical surface element used for both frequencies, the similar spatial sensitivities can also benefit the absolute quantification of the Tissue Sodium Concentration (TSC) [17].

An extended trap circuit approach was used in this paper, wherein a single loop was tuned to both ${ }^{1} \mathrm{H}$ and ${ }^{23} \mathrm{Na}$ frequencies as described in previous designs, but with both signal components passed to the MR system's preamplifiers via separate coaxial cables. The advantages of the newly-developed resonator for interleaved ${ }^{23} \mathrm{Na}$ - and ${ }^{1} \mathrm{H}-\mathrm{MRI}$ were then demonstrated in a rodent acute stroke model.

\section{EXPERIMENTAL}

The design philosophy used for the surface resonator is described in this section, together with specific explanation of the adjustment process employed to optimize the inter-channel decoupling.

\section{Circuit Design Principle}

The electronic design principle of the double-tuned detector element (resonator without any connected coaxial cable) is illustrated in Figure 1a. The basic rf circuit components in this trap circuit design are the detector inductance $\left(\mathrm{L}_{\text {Det }}\right)$, the trap circuit inductance $\left(\mathrm{L}_{\mathrm{Tr}}\right)$, the trap circuit capacitance $\left(\mathrm{C}_{\mathrm{Tr}}\right)$, the ${ }^{23}$ Na-resonance frequency-determining capacitor $\left(\mathrm{C}_{\mathrm{Na}}\right)$, and the ${ }^{1} \mathrm{H}$-resonance frequency-determining capacitor $\left(\mathrm{C}_{\mathrm{H}}\right)$. The higher level of complexity in this circuit compared to that generally used derives from the parallel capacitor $\mathrm{C}_{\mathrm{H}}$, which provides a balanced ground connection and two frequency-dependent live connection paths on the resonance circuit.

To understand the double-tuning capability of this circuit, one must find the frequency-dependent current paths determined by the capacitive and inductive impedances 
'seen' at 79.4 and $300 \mathrm{MHz}$, which correspond to the ${ }^{23} \mathrm{Na}$ and ${ }^{1} \mathrm{H}$ frequencies respectively at $7 \mathrm{~T}$. For instance at $300 \mathrm{MHz}$, the impedance of the ${ }^{23} \mathrm{Na}$ capacitor $\left(\mathrm{C}_{\mathrm{Na}}=20.4 \mathrm{pF}\right)$ is low at $26 \Omega$ compared to $113 \Omega$ for $\mathrm{C}_{\operatorname{Tr}}(4.7 \mathrm{pF})$ and $75 \Omega$ for $\mathrm{L}_{\operatorname{Tr}}(40 \mathrm{nH})$. For subsequent considerations the ${ }^{23} \mathrm{Na}$-resonance frequency-determining capacitor $\mathrm{C}_{\mathrm{Na}}$ can thus be neglected, because it has nearly no effect on the higher ${ }^{1} \mathrm{H}$-resonance frequency. Therefore, the electronic circuit at $300 \mathrm{MHz}$ can be simplified as shown in Figure 1b. From this simplified circuit diagram, one can approximate the resonance condition at $300 \mathrm{MHz}$ via:

$$
f_{300 M H z}=\frac{1}{2 \pi \sqrt{\left(L_{D e t} \| L_{T r}\right) \cdot\left(C_{H} \| C_{T r}\right)}}
$$

\section{(Equation 1)}

At the ${ }^{23} \mathrm{Na}$ resonance frequency of $79.4 \mathrm{MHz}$, the impedance of $\mathrm{C}_{\mathrm{H}}(5 \mathrm{pF})$ and $\mathrm{C}_{\mathrm{Tr}}(4.7 \mathrm{pF})$ are high at approximately $400 \Omega$ each, compared to $20 \Omega$ for the trap circuit inductor $\mathrm{L}_{\operatorname{Tr}}$ $(\sim 40 \mathrm{nH})$. Consequently, $\mathrm{C}_{\mathrm{H}}$ and $\mathrm{C}_{\mathrm{Tr}}$ remain effectively open for the low ${ }^{23}$ Na-resonance frequency. The electronic circuit at $79.4 \mathrm{MHz}$ can thus be approximated as shown in Figure 1c, with the resonance condition at this frequency given by:

$$
f_{79 M \mathrm{MHz}}=\frac{1}{2 \pi \sqrt{\left(L_{D e t}+L_{T r}\right) \cdot\left(C_{N a}\right)}}
$$

(Equation 2)

To enable optimum coil performance, both RF cables (that is, for the ${ }^{1} \mathrm{H}$ and ${ }^{23} \mathrm{Na}$ channels) must be sufficiently decoupled from each other. Furthermore, it is highly desirable if tuning and matching can be designed to be independently adjustable in situ within the MRI system, so that adjustments performed on one channel have no effects on the other channel's resonance properties. These requirements impose a challenge on designing the transceiver coil with a high degree of RF stability. The stability of the resonance frequency, in turn, was highly dependent on the ground potential balance, which was adjusted by the deliberate creation of zero potential "null" spots (also referred to as virtual ground [26]) at specified locations on the resonance structure. Null spots are locations on the coil at which the measurable potential variation remains zero when a frequency-specific emf is induced in the coil. The creation of such frequency-dependent null spots allows one to connect the ${ }^{1} \mathrm{H}$ cable to a ${ }^{23} \mathrm{Na}$ null spot and, vice versa, the ${ }^{23} \mathrm{Na}$ cable to a ${ }^{1} \mathrm{H}$ null spot, in order to achieve maximal channel decoupling. Given the wide 
separation in resonant frequencies for ${ }^{23} \mathrm{Na}$ and ${ }^{1} \mathrm{H}$, one can exploit the frequency-dependent inductive and capacitive behavior of the RF circuit components (i.e. inductors and capacitors) to create a ${ }^{1} \mathrm{H}$ null spot in a ${ }^{23} \mathrm{Na}$ hot spot and a ${ }^{23} \mathrm{Na}$ null spot in a ${ }^{1} \mathrm{H}$ hot spot. The use of this principle significantly improved the decoupling of the two channels.

In all simple and symmetric $L C$ parallel resonators (e.g.: single inductor and single capacitor), a null spot exists at resonance frequency at approximately half of the inductor length, and can be empirically found by tapping along the inductor with a metal screw driver and simultaneously observing the $s_{11}$-reflection measurement on the network analyzer screen. The resonance curve will remain unchanged if the resonator is tapped at a null spot, whereas a change in frequency will be observed if tapped at a hot spot due to leakage current effects and concomitant resonance property changes. To generate additional null spots, the principle of split tuning capacitors is commonly employed [26]. The connection of ground to a null spot guarantees optimized resonator stability with regards to matching and tuning.

The fact that null spots can be located at different frequency-dependent physical positions on the resonance circuit was exploited when connecting the RF cables to the double-tuned surface resonator. By attaching the ${ }^{23} \mathrm{Na}$ frequency output cable to a ${ }^{1} \mathrm{H}$ null spot, the drain of ${ }^{1} \mathrm{H}$ signal through that additional conductor path was minimized. This splitting of the null spots is illustrated in Figure 2. The ${ }^{23} \mathrm{Na}$ capacitors $\mathrm{C}_{\mathrm{Na} 1}$ and $\mathrm{C}_{\mathrm{Na} 2}$ possessed low impedance at the ${ }^{1} \mathrm{H}$ frequency and thus behaved like a short circuit at the higher frequency. Therefore, the ${ }^{1} \mathrm{H}$ frequency's null spot position remained unchanged at half the trap circuit's inductance, that is, in between the trap circuit capacitor's electrodes $\left(\mathrm{C}_{\mathrm{Tr}}\right)$. Bearing these design principles in mind, the surface coil was developed as described in the following section.

\section{Practical double-tuned ${ }^{23} \mathrm{Na}^{1}{ }^{1} \mathrm{H}$ surface coil design}

The detector part of the coil was manufactured using copper wire (1.5 mm diameter) wound to two windings of $20 \mathrm{~mm}$ and $30 \mathrm{~mm}$ inner diameter (i.d.) and anatomically-shaped over a semi-cylindrical fibreglass tube $(42 \mathrm{~mm}$ i.d.). The coil was tuned to approximately $180 \mathrm{MHz}$ (close to the mean of the two target frequencies) by a $4.7 \mathrm{pF}$ capacitance. To facilitate a balanced ground connection, the $4.7 \mathrm{pF}$ capacitance was split into two $10 \mathrm{pF}$ 
(CHB series, TEMEX, France) series capacitance values $\left(\mathrm{C}_{\mathrm{H} 1}\right.$ and $\left.\mathrm{C}_{\mathrm{H} 2}\right)$. The inductance of the detector loop was measured to be $166 \mathrm{nH}$.

Parallel to the series capacitors, a second capacitor $\left(\mathrm{C}_{\mathrm{Na}}\right)$ and a trap circuit composed of the trap inductance $\left(\mathrm{L}_{\text {Trap }}\right)$ and capacitance $\left(\mathrm{C}_{\text {Trap }}\right)$ were inserted and the conductor path was extended to the circuit board. The parallel combining of this coil and the trap inductance impairs the proton sensitivity slightly, but, of course, will keep the sodium sensitivity.

The trap circuit inductor was composed of a $60 \mathrm{~mm}$ long, $1 \mathrm{~mm}$ diameter copper-beryllium wire, wound on $6 \mathrm{~mm}$ diameter drill bit (1.5 windings, resulting in an inductance of approximately $40 \mathrm{nH}$ ). The trap circuit capacitor was chosen in such a way that $300 \mathrm{MHz}$ was achieved in conjunction with the capacitors $\mathrm{C}_{\mathrm{H} 1}$ and $\mathrm{C}_{\mathrm{H} 2}$. The final trap circuit capacitance was determined to be $4.7 \mathrm{pF}\left(\mathrm{C}_{\text {Trap }}\right)$ and resulted in a trap circuit resonance of $360 \mathrm{MHz}$. One resonance peak thus resulted at approximately $300 \mathrm{MHz}$ due to the total coil capacitance of $10 \mathrm{pF}\left(\mathrm{C}_{\mathrm{H}}\right.$ of $5 \mathrm{pF}$ in parallel to $\mathrm{C}_{\text {Trap }}$ of $\left.4.7 \mathrm{pF}\right)$ and the total coil inductance of $32 \mathrm{nH}$ ( $\mathrm{L}_{\text {detector }}$ of $166 \mathrm{nH}$ in parallel to $\mathrm{L}_{\text {Trap }}$ of $40 \mathrm{nH}$ ). The lower resonance frequency of approximately $79 \mathrm{MHz}$ was achieved via the series detector and trap circuit inductance and the ${ }^{23} \mathrm{Na}$ frequency-determining capacitance.

The resulting structure, with approximately $206 \mathrm{nH}$ inductance and $20 \mathrm{pF}$ capacitance, resonated at $80 \mathrm{MHz}$ because the capacitors $\mathrm{C}_{\mathrm{H} 1}$ and $\mathrm{C}_{\mathrm{H} 2}$ had only minor influence on the lower resonance frequency due to their low capacitive value $(\sim 5 \mathrm{pF})$ and subsequently high impedance at 79.4 MHz. The $\mathrm{C}_{\mathrm{Na}}$ capacitor was also split into capacitors $\mathrm{C}_{\mathrm{Na} 1}$ and $\mathrm{C}_{\mathrm{Na} 2}$. They were placed symmetrically with respect to the originally inserted tuning capacitors $\mathrm{C}_{\mathrm{H} 1}$ and $\mathrm{C}_{\mathrm{H} 2}$.

It was also important to block remaining components of the undesired second frequency in the respective RF coaxial cable path to limit signal losses. The final coil and circuit design is shown in Figure 3. A ${ }^{1} \mathrm{H}$ trap circuit was inserted in between the ${ }^{23} \mathrm{Na}$ terminal point and the matching trimmer capacitor $(0.5-6 \mathrm{pF}$, model NMQM6GE, Voltronics, USA) to which the coaxial cable for transmitting the measured ${ }^{23} \mathrm{Na}$ MR signal to the preamplifier was fixed. The trap circuit was tuned to $300 \mathrm{MHz}$ by a $0.3-3.5 \mathrm{pF}$ trimmer capacitor (AT5800, TEMEX, France), a $3.3 \mathrm{pF}$ fixed value capacitor, and a 1.5 winding $0.8 \mathrm{~mm}$ diameter copper wire wound on $6 \mathrm{~mm}$ drill bit (approximately $40 \mathrm{nH}$ ).

For ${ }^{23} \mathrm{Na}$ tuning purposes, a tuning trimmer capacitor $(0.5-6 \mathrm{pF}$, NMQM6GE, Voltronics, USA) was mounted in parallel to $\mathrm{C}_{\mathrm{Na} 1}$ and $\mathrm{C}_{\mathrm{Na} 2}$. Tuning of the ${ }^{1} \mathrm{H}$ frequency 
was achieved via a custom-designed variable inductor. By inserting a brass tuning rod into the windings of the trap circuit inductance, which could be screwed in and out remotely, the resonance frequency could be accurately adjusted to $300 \mathrm{MHz} .{ }^{1} \mathrm{H}$ matching was achieved through a trimmer capacitor (0.5 - 6 pF, NMQM6GE, Voltronics, USA). Once all coil components were mounted, the optimization process was performed as follows.

The ${ }^{1} \mathrm{H}$ frequency was tuned by varying the fixed capacitors $\mathrm{C}_{\mathrm{H} 1}$ and $\mathrm{C}_{\mathrm{H} 2}$ (that is, by alternately swapping in different-valued capacitors) and monitoring the result using a pick-up loop. The RF cables for ${ }^{1} \mathrm{H}$ and ${ }^{23} \mathrm{Na}$ were then connected to the respective matching capacitors. In a second step, the inter-channel decoupling was adjusted by inserting the $300 \mathrm{MHz}$ trap circuit into the ${ }^{23} \mathrm{Na}$ cable path. An $s_{21}$-transmission measurement below $-30 \mathrm{~dB}$ was taken to indicate acceptable ${ }^{1} \mathrm{H} /{ }^{23} \mathrm{Na}$ inter-channel decoupling and hence maximal ${ }^{23} \mathrm{Na}$ Q-factor was achieved. The decoupling at the 79.4 $\mathrm{MHz}$ frequency was then adjusted by varying the $\mathrm{C}_{\mathrm{Na} 1}$-to- $\mathrm{C}_{\mathrm{Na} 2}$-ratio, whereby the condition $\mathrm{C}_{\mathrm{Na} 1}>\mathrm{C}_{\mathrm{Na} 2}$ had to be fulfilled $\left(\mathrm{C}_{\mathrm{Na} 1}=64 \mathrm{pF}\right.$ and $\left.\mathrm{C}_{\mathrm{Na} 2}=30 \mathrm{pF}\right)$. This compensation was necessary because insertion of the trap circuit inductance and connection of the coaxial cables to the resonator invariably lead to a shift of the ${ }^{23} \mathrm{Na}$ null spot (it was no longer located between $\mathrm{C}_{\mathrm{Na} 1}$ and $\mathrm{C}_{\mathrm{Na} 2}$, but rather was below $\mathrm{C}_{\mathrm{Na} 2}$ ). The ratio was deemed to be adequately adjusted when the dip in the $s_{21}$-transmission curve was measured below $-30 \mathrm{~dB}$ at $79.4 \mathrm{MHz}$. To measure the resonance properties of the final coil design, both RF cables were connected to a network analyzer (model E5061A, Agilent Technology, USA) and the $s_{11}$-reflection and transmission curves were acquired.

The mechanical stability of the coil was an important factor in the coil design to ensure optimum performance under in vivo measurement conditions. Once the resonator was placed on top of the sample and moved into the magnet bore, the resonance properties changed due to interactions with the scanner environment (for example, with the gradients) and with the sample itself. Therefore, variable tuning and matching capacitors were mechanically inbuilt into each channel of the transceiver coil in order to restore the optimum resonance properties at the site of the MRI experiment. Accessing one of the small $6 \mathrm{~mm}$ diameter trimmer capacitors from a distance of $>1 \mathrm{~m}$ was difficult due to a lack of space and light in the magnet. Thus, it was important that those capacitors could be remotely varied from outside the magnet bore. To do this, $30 \mathrm{~cm}$ long fibreglass rods were attached to the variable components via custom-made plastic supports that prevented breakage of the brittle glass capacitors. 
The SNR of the magnitude images was calculated as

$$
S N R=1.25 \frac{\bar{S}}{\bar{N}}
$$

(Equation 3)

where $\bar{S}$ and $\bar{N}$ are the mean signal amplitude in a central region of interest (ROI) and the mean noise in a background ROI, respectively [20].

The SNR of the resonator was improved by double-winding the coil element, while shaping the plane of the coil to better fit around the head of a rat further increased the SNR at depth. Thick copper wire was used in preference to thin foil, as this allowed for adequate separation between the individual coil loops, which is necessary in order to minimize crosstalk (the proximity-effect) deriving from the required high capacitive impedance $(>1 \mathrm{k} \Omega$ ) between the two windings at the low frequency. The use of more loops degraded the characteristics of the coil due to the small dimensions involved.

\section{MRI in Vivo Experiments}

The ${ }^{1} \mathrm{H}$ and ${ }^{23} \mathrm{Na}$ image quality of the resonator was demonstrated by acquiring high spatial resolution images of a healthy 1.5 year old Sprague Dawley rat (400 g) using a 7T Bruker system (BioSpec with AV3 electronics, Bruker BioSpin GmbH, Ettlingen, Germany), as follows. ${ }^{23} \mathrm{Na}$ : 3D-FLASH sequence with TR / TE $=22.1 / 5.1 \mathrm{~ms}$, with an asymmetric $20 \%$ partial echo, $45^{\circ}$ flip angle at $2 \mathrm{~mm}$ sample depth, $125 \mu$ s block pulse, $5 \mathrm{kHz} \mathrm{BW}$, matrix size of $80 \times 80 \times 80$, spatial resolution of $1 \times 1 \times 4 \mathrm{~mm}^{3}$ (corresponding to a voxel size of $4 \mu \mathrm{l}$ - later two-fold $3 \mathrm{D}$ zero-filled to $0.5 \times 0.5 \times 2 \mathrm{~mm}^{3}$ ), 17 averages resulting in a $\mathrm{T}_{\mathrm{acq}}$ of $40 \mathrm{~min} 10 \mathrm{~s}$. The long acquisition time allowed for a comparison with the current state-of-the-art ${ }^{23} \mathrm{Na}$-imaging of the rat brain [20]. The low bandwidth was used to maximize the SNR, and resulted in the relatively long TE. The use of a short TR further reflects that used in the majority of rodent ${ }^{23} \mathrm{Na}$ studies [20, 27, 28], whereby the maximal SNR per unit acquisition time may be achieved by imaging in the steady state considering that the $\mathrm{T}_{1}$ of ${ }^{23} \mathrm{Na}$ nuclei in vivo is $\sim 50 \mathrm{~ms}$. ${ }^{1} \mathrm{H}$ : $2 \mathrm{D}$-RARE sequence with $\mathrm{TR} / \mathrm{TE}_{\text {eff }}=$ $2500 / 33 \mathrm{~ms}$, spatial resolution $0.23 \times 0.23 \times 2.0 \mathrm{~mm}$, RARE factor $8, \mathrm{~T}_{\text {acq }}$ of $5 \mathrm{~min} 20 \mathrm{~s}$. This experiment was carried out under appropriate animal license and with ethics approval.

A second in vivo experiment was carried out (using a different 7T Bruker system with the older AV1 electronics) on a rodent model of focal cerebral ischemia to further demonstrate the utility of the resonator. The intraluminal thread model of middle cerebral artery 
occlusion (MCAO) was used to induce an experimental stroke, wherein the right MCA was occluded in one male Sprague Dawley rat (4 month old, bodyweight $\sim 300 \mathrm{~g}$ ). This experiment was performed under license from the UK Home Office and was subject to the Animals (Scientific Procedures) Act, 1986. Blood pressure, heart rate, body temperature and blood gases were monitored and maintained within normal limits. The older electronics on this system necessitated slight changes to the ${ }^{23} \mathrm{Na}$ imaging protocol, as follows: $\mathrm{TR} / \mathrm{TE}=20 / 2.1 \mathrm{~ms}$, matrix size of $64 \times 64 \times 32,10 \%$ partial echo acquisition and $\mathrm{BW}=4 \mathrm{kHz}$. Other parameters remained unchanged. The acquisition time was reduced to 5 minutes in order to obtain high temporal information during the critical acute phase of the experimental stroke. ${ }^{1} \mathrm{H}$ DWI images were acquired using an EPI sequence with TR $/ \mathrm{TE}=4000 / 32 \mathrm{~ms}, 4 \mathrm{~b}$-values with $\mathrm{b}_{\max }=600 \mathrm{~s} / \mathrm{mm}^{2}$, voxel size $0.25 \times 0.25 \times 1.9$ $\mathrm{mm}^{3}, 8$ slices with $0.1 \mathrm{~mm}$ gap, 8.5 minute acquisition. ${ }^{1} \mathrm{H}$ PWI images were also acquired prior to the rat's sacrifice by swopping the resonator with a standard dual resonator system (72 $\mathrm{mm}$ i.d. linear volume resonator and $20 \mathrm{~mm}$ i.d. receive-only surface coil) in a pseudocontinuous arterial spin labelling (pCASL) [29, 30] EPI-based experiment, with: $\operatorname{TR}($ labelling pulse $)=60 \mathrm{~ms}, 50$ pulses, with slice selective labelling around the neck and above the head, EPI read-out with TR / TE $=4000 / 22 \mathrm{~ms}$, in-plane resolution $0.26 \times 0.26$ $\mathrm{mm}^{2}$ for a single slice with $2 \mathrm{~mm}$ slice thickness, $\mathrm{T}_{\mathrm{acq}}=2 \mathrm{~min}$ per slice. At the end of scanning experiment the animal was sacrificed by transcardial perfusion fixation using $4 \%$ paraformaldehyde in a phosphate buffer. Following fixation, the brain was harvested, processed and embedded in paraffin wax and subsequently sectioned at $6 \mu \mathrm{m}$ and stained with haematoxylin and eosin for histological analysis. ${ }^{23} \mathrm{Na}$ images were measured from as early as 20 minutes up to 5 hours after MCAO, with ADC measurements performed in between. At $\sim 6$ hrs after the stroke was induced, ischaemic core tissue was defined as region of infarction identified in the histology slides, while still-viable, but underperfused tissue (penumbra) was defined as the mismatch between regions of perfusion deficit $(<57 \%$ contralateral perfusion [31]) and ischaemic core tissue.

Linear regression was performed on the time-course data for the ${ }^{23} \mathrm{Na}$ signal and ${ }^{1} \mathrm{H}$ ADC measurements using the following equation:

$$
y(\vec{r}, t)=a(\vec{r}, t) \cdot t+b(\vec{r}, t)
$$

(Equation 4),

where $y$ was the ${ }^{23} \mathrm{Na}$ signal or the ${ }^{1} \mathrm{H}$ ADC in voxel position $\vec{r}$ at measurement time, $t$, with slope, $a$, and offset (intercept), $b$, being the linear regression results. 


\section{RESULTS}

The reflection and transmission curves for both channels of the home-built coil are presented in Figure 4, demonstrating the high degree of isolation (in excess of $-30 \mathrm{~dB}$ ) between the ${ }^{23} \mathrm{Na}$ and ${ }^{1} \mathrm{H}$ channels. All other resonator characteristics are listed in Table 1. Note the significantly higher loaded Q-factor at the ${ }^{23} \mathrm{Na}$-frequency of 117.

The high spatial resolution ${ }^{1} \mathrm{H}$ and ${ }^{23} \mathrm{Na}$ images acquired with the home-built resonator are presented in Figure 5, demonstrating the excellent imaging performance of the detector. Notice the strong ${ }^{23} \mathrm{Na}$ signal from blood vessels and the suppressed ${ }^{23} \mathrm{Na}$ signal from tissue with shorter transversal relaxation time, $\mathrm{T}_{2 \mathrm{~s}}$, (for example, gray and white matter regions of the brain) due to the use of a relatively long TE of $5.1 \mathrm{~ms}$. An average SNR of 15 was measured in brain tissue and 45 in ventricular cerebrospinal fluid. Note the clear gap between the brain and the facial tissue, as well as the clear delineation of blood and CSF filled regions, which was not visible in previous studies [20]. Two reference vials were fixed on top of the detector coil in order to assess displacement errors in consecutive experiments and also to allow for normalization of the image values in subsequent analyses. The signal intensity was relatively homogeneous across the rat's brain, although signal drop-off can be observed with larger coil-sample distances, for example in the lower parts of the brain, which nonetheless remain visible.

For the stroke experiment, the relative ${ }^{23} \mathrm{Na}$ images and quantitative ADC maps at different time points after the stroke was induced are shown in Figure 7a. The slope and offset maps for the ${ }^{23} \mathrm{Na}$ and ${ }^{1} \mathrm{H}$ ADC data sets were computed and are presented in Figure 7b. The histology line diagram delineating the region of infarcted tissue and ${ }^{1} \mathrm{H}$ perfusion weighted image at $6 \mathrm{hrs}$ after stroke onset time are presented in Figure 7c. At the time of sacrifice, the tissue damage revealed by histology was evident in cortical and subcortical regions. The perfusion deficit was found to extend slightly further into the upper cortex. The area of significantly-increased ${ }^{23} \mathrm{Na}$ signal and decreased ADC closely matched the area of infarct identified from histology, while significantly decreased ${ }^{23} \mathrm{Na}$ was measured in the mismatch regions defined by the perfusion/histology mismatch approach (see arrows in the respective images). 


\section{DISCUSSION}

The circuit design described in the paper produced a significant improvement in achievable in vivo SNR compared to the current state-of-the art design [20] by specifically separating and ensuring optimal decoupling between the ${ }^{1} \mathrm{H}$ and ${ }^{23} \mathrm{Na}$ channels. The design also benefits from an ability to independently tune and match each channel, thereby ensuring that an optimal sensitivity is achieved for each sample imaged. Re-adjusting the resonator components after switching from one nucleus to the other was thus avoided.

The use of a two-winding, thick wire detector element instead of a one winding copper strip resulted in an effective loaded Q-factor increase to 117 in the ${ }^{23} \mathrm{Na}$ channel; only half as high loaded Q-factor of 64 was achieved with a single loop by others [20]. However, the loaded Q-factor of 75 measured at the ${ }^{1} \mathrm{H}$ frequency was nearly identical to 71 measured by a single winding loop at $170 \mathrm{MHz}$. Although the ${ }^{23} \mathrm{Na}$ channel's unloaded Q-factor was increased, the loaded Q-factors were similar at the ${ }^{1} \mathrm{H}$ frequency, indicating that the double-winding had no effect on the coil's sensitivity at that high frequency. In this case, any improvement stemming from the double winding may have been cancelled out by either the closeness of the coil windings (proximity effect) or the increased coil resistance. Hence, while the choice of a two turns coil is obviously beneficial at the sodium frequency, it increases the detector impedance at $300 \mathrm{MHz}$ resulting is a slight compromise for the proton sensitivity. Care must be exercised with such bench-level measurements, since they neglect the actual noise contribution for the various geometrical conditions. A further consideration when comparing resonators arises from the fact that the multiple-winding has a complex influence on the detector losses due to an increase in coil inductance and a subsequent decrease in coil capacitance. The lower value capacitor needed for a two-turn coil is generally of much lower $\mathrm{Q}$ than the capacitor value needed for a one-turn. By double-winding the resistive losses of the trap inductor were also reduced relative to the occurring resistive losses in the larger detector inductance. Finally, the solder and trap circuit resistance will contribute more significantly with the one turn coil. All these factors may explain why the Q-factor was higher for the two turns coil as compared to the single-turn, which makes it difficult to attribute the Q-factor improvement solely to the number of turns. Although the use of more than two loops increases the unloaded Q-factor even further, in practice it was found that the increase in conductor surface area with more 
windings tended to increase dielectric losses and produced no improvement in the loaded Q-factor. The coil geometry presented herein was found to be optimum for the chosen frequency of $79.4 \mathrm{MHz}$ and with an effective coil diameter of $26 \mathrm{~mm}$.

Anatomical shaping of the double-winding surface coil further increased the signal sensitivity, which was reflected by the overall sensitivity improvement in the ${ }^{23} \mathrm{Na}$ channels and the ability to image with excellent SNR through to the base of the brain. The high spatial resolution is demonstrated by the clear gap in signal intensity, corresponding to the skull, between the brain and the facial tissue in the ${ }^{23} \mathrm{Na}$ images, which was not apparent in $\mathrm{Na}$ images acquired at $21 \mathrm{~T}$ in a recent rat brain study due to smearing artifacts in the images, despite a supposedly higher voxel resolution of $0.125 \mu 1$ and similar SNR of 47 achieved in an $87 \mathrm{~min}$ acquisition time [32].

The double-tuned two-port surface coil design also demonstrated excellent performance from the point of view of both coil stability and on-site flexibility in its usage (i.e. tuning, matching and inter-channel decoupling). A comparison was made between this coil and the current state-of-the-art resonator in rat brain ${ }^{23} \mathrm{Na}$ imaging as described in the published literature, comparing voxel sizes, image acquisition times, field strengths used, and SNR values achieved. In order to compare SNR values measured in the current study with those measured elsewhere, the SNR values measured in the ventricles in the brain in each study were converted to an 'equivalent SNR', by multiplying the measured values with a correction factor taking into account the different field strengths [26], acquisition times and voxel resolutions used in each study, such that they could be compared to the current study (that is, commensurate with all images being acquired at $7 \mathrm{~T}$ in 40 minutes with $4 \mu 1$ voxel size, respectively). Thus, in the study of Alecci et al. [20], their measured SNR of 11 acquired at $4 \mathrm{~T}$ (correction factor 1.75) with $8 \mu$ l voxel size (correction factor 0.5 ) and $35 \mathrm{~min}$ acquisition time (correction factor 1.07) converts to an equivalent SNR of 10 compared to 45 in the current study. A ten-fold improvement in equivalent SNR was achieved compared to a recently published technical note [33], where a novel triple ${ }^{1} \mathrm{H} /$ ${ }^{23} \mathrm{Na} /{ }^{39} \mathrm{~K}$ coil was employed. In this study, it is likely that a compromise was reached between the SNR efficiencies for the ${ }^{23} \mathrm{Na}$ and ${ }^{39} \mathrm{~K}$ channels, perhaps focusing on the latter, less sensitive nuclei at the expense of the ${ }^{23} \mathrm{Na}$ nuclei's sensitivity. The SNR can be further optimized through the use of an ultra-short TE sequence, such as the recently published density adapted radial technique [34]. 
The newly-developed coil described herein proved capable of acquiring high SNR ${ }^{23} \mathrm{Na}$ brain images in vivo with high resolution within reasonable acquisition times of 10 minutes in a rat stroke study. ADC maps were also acquired without having to change the resonator system between scans. A clear increase of the ${ }^{23} \mathrm{Na}$ signal in permanently damaged tissue over time was observed, which presented as a ${ }^{23} \mathrm{Na}$ slope of $\sim 20 \% / \mathrm{h}$, while only minor changes were observable within the hypointense regions of the ADC maps. More interestingly, ${ }^{23} \mathrm{Na}$ was decreased by $20 \%$ in underperfused, but still viable penumbral tissue. Hence, low ${ }^{23} \mathrm{Na}$ signal could potentially serve as a tissue viability marker during acute stroke. Future experiments will focus on investigating this effect on a larger group of animals.

Limitations of the transceiver surface resonator arise, however, when quantitative measurements are required, because transceiver coils generate an inherently inhomogeneous $B_{1}$-field corresponding to the detector element's sensitivity profile. To overcome this problem, adiabatic pulses may be employed to minimize the inherent $\mathrm{B}_{1}$ inhomogeneity. Another possibility to quantify TSC would be to use the ${ }^{1} \mathrm{H}$ sensitivity profile to compensate the ${ }^{23} \mathrm{Na}$ coil sensitivity, as has been demonstrated elsewhere [17]. , To a first approximation, the two channels may be assumed to have identical spatial receive sensitivities; however, as the dielectric losses due to homogeneous loading vary with frequency, the spatial distribution of the flip angles can vary with identical transmit powers and thus this would need to be adjusted for each frequency for every experimental set-up. This could be achieved by placing a reference vial on top of the resonator and by adjusting $180^{\circ}$ flip angle (signal saturation line) in identical spatial location in both the ${ }^{23} \mathrm{Na}$ and ${ }^{1} \mathrm{H}$ images. However, frequency-dependent interferences in the sample such as dielectric resonances, stationary waves, conductivity effects, and heterogeneous loading, may cause further differences in the flip angle distribution between both channels and render accurate TSC quantification more problematic.

Given the availability of MRI animal scanners at ultra high fields, the coil design described herein could be easily adapted for fields higher then $7 \mathrm{~T}$, because the interchannel decoupling was achieved via the null spot method which eliminated possible losses introduced by the RF components of a decoupling circuit. Indeed, this design technique can equally be used to construct coils for the imaging of other nuclei such as ${ }^{17} \mathrm{O},{ }^{13} \mathrm{C},{ }^{31} \mathrm{P}$, ${ }^{39} \mathrm{~K}$, and ${ }^{43} \mathrm{Ca}$, etc. 
In conclusion, the acquisition of ${ }^{23} \mathrm{Na}$ images of the rat brain with significantly greater spatial resolution compared to recently published small animal ${ }^{23} \mathrm{Na}$ MRI studies was described. The newly-developed coil system will allow for extensive studies of total

${ }^{23} \mathrm{Na}$ - and intra-cellular ${ }^{23} \mathrm{Na}$-concentration changes in animal models of common human diseases with high spatio-temporal resolution.

\section{Acknowledgements}

This work was financially supported by Science Foundation Ireland (05/RFP/PHY006). 
Table 1: Characteristics of the double-tuned two-port surface resonator from bench-level based measurements.

\begin{tabular}{cccccc}
\hline \hline & & & $\begin{array}{c}\text { Dynamic } \\
\text { tuning range } \\
\text { (in MHz) }\end{array}$ & $\begin{array}{c}\text { Decoupling } \\
\text { from }{ }^{23} \mathrm{Na} \text { or } \\
{ }^{1} \mathrm{H} \text { (in dB) }\end{array}$ \\
\hline & & & & & \\
${ }^{23} \mathrm{Na}$ & 140 & 117 & 1.2 & 76.8 to 84.6 & 35 \\
${ }^{1} \mathrm{H}$ & 84 & 75 & 1.12 & 299 to 303 & 34 \\
\hline \hline
\end{tabular}


(a)

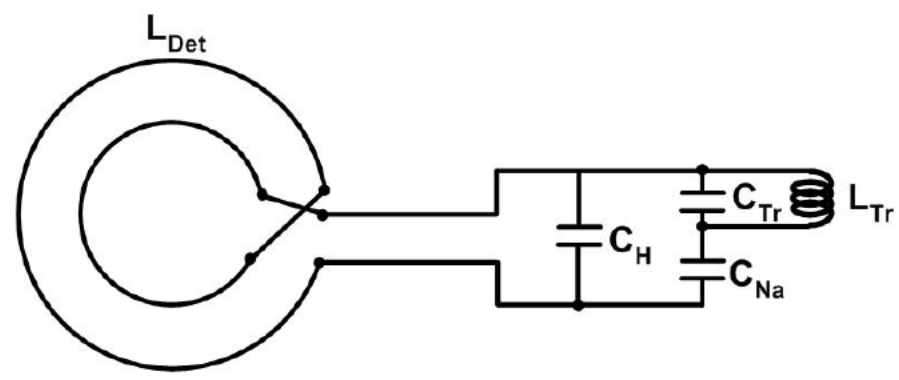

(b)

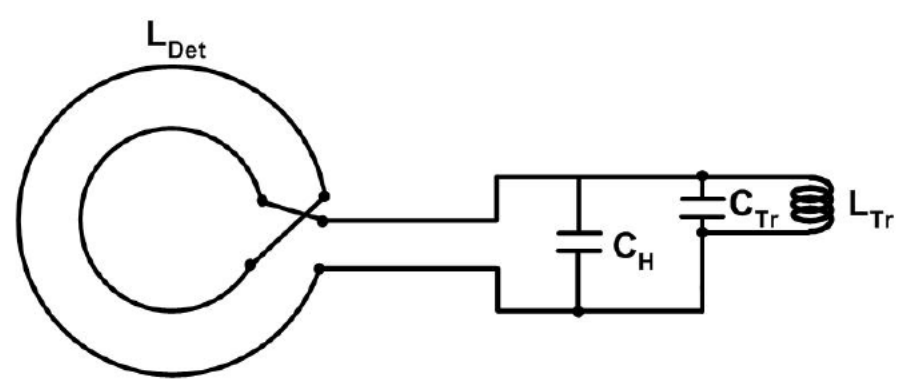

(c)

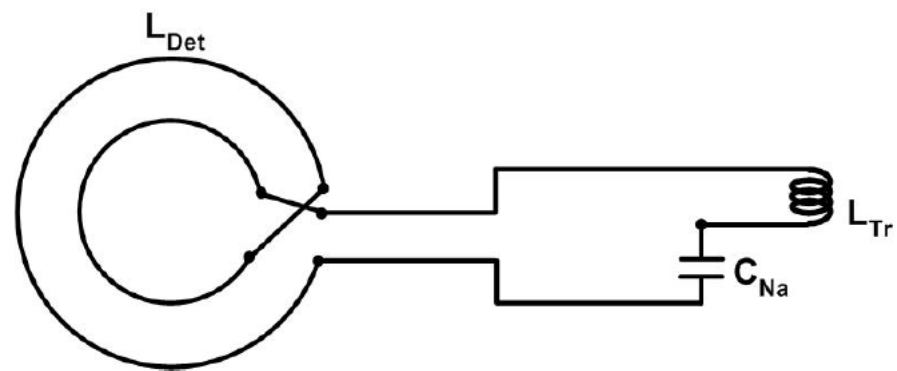

Figure 1: (a) Principle electronic circuit for the two-port double-tuned surface coil and the circuit components 'seen' by (b) the ${ }^{1} \mathrm{H}$ - and (c) the ${ }^{23} \mathrm{Na}$-frequency. 


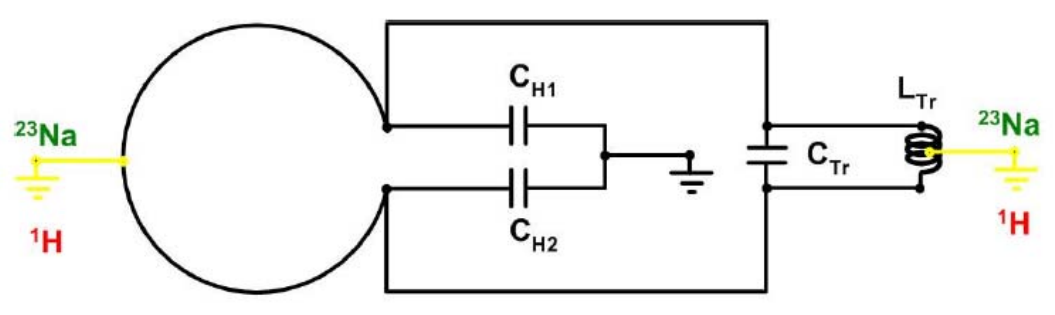

(a)

b)

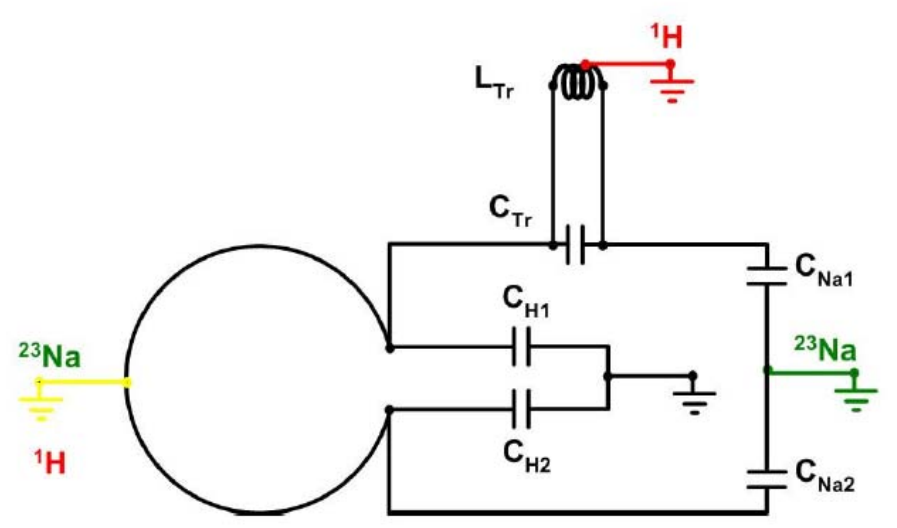

Figure 2: Circuit design of the double-tuned two port surface coil demonstrating the double-tuning and null spot splitting within the circuitry loop. Colored ground connectors represent the available null spot positions for the respective ${ }^{23} \mathrm{Na}$ and ${ }^{1} \mathrm{H}$ resonance frequencies. Please note that the geometric symmetry of all components in the developed resonator must coincide with the pictured circuit diagram, i.e. symmetry line through ground, $\mathrm{C}_{\mathrm{Tr}}$, and $\mathrm{L}_{\mathrm{Tr}}$. (a) Null spots exist at half the inductor length of the detector element and at half the length of $\mathrm{L}_{\mathrm{Tr}}$ for both frequencies. (b) The trap circuit is moved away from the symmetry line by adding split ${ }^{23} \mathrm{Na}$ tuning capacitors, $\mathrm{C}_{\mathrm{Na} 1}$ and $\mathrm{C}_{\mathrm{Na} 2}$, into the trap circuit path. $\mathrm{C}_{\mathrm{Na} 1}$ and $\mathrm{C}_{\mathrm{Na} 2}$ are effectively short circuits for the ${ }^{1} \mathrm{H}$ frequency and therefore the null spot for ${ }^{1} \mathrm{H}$ and ${ }^{23} \mathrm{Na}$ moves into different physical positions on the resonator. The reactance of $\mathrm{C}_{\mathrm{Tr}}$ dominates the creation of ${ }^{1} \mathrm{H}$ virtual ground to in between its capacitor plates and hence approximately to half length of $\mathrm{L}_{\mathrm{Tr}}$. Since the ${ }^{23} \mathrm{Na}$ capacitors dominate the trap circuit path at the ${ }^{23} \mathrm{Na}$ frequency, the null spot for the ${ }^{23} \mathrm{Na}$ frequency remains near the symmetry line. The ration of the split ${ }^{23} \mathrm{Na}$ capacitors has to be chosen appropriately, when connecting wires to the ${ }^{1} \mathrm{H}$ and ${ }^{23} \mathrm{Na}$ terminals as described in the practical resonator design section. 


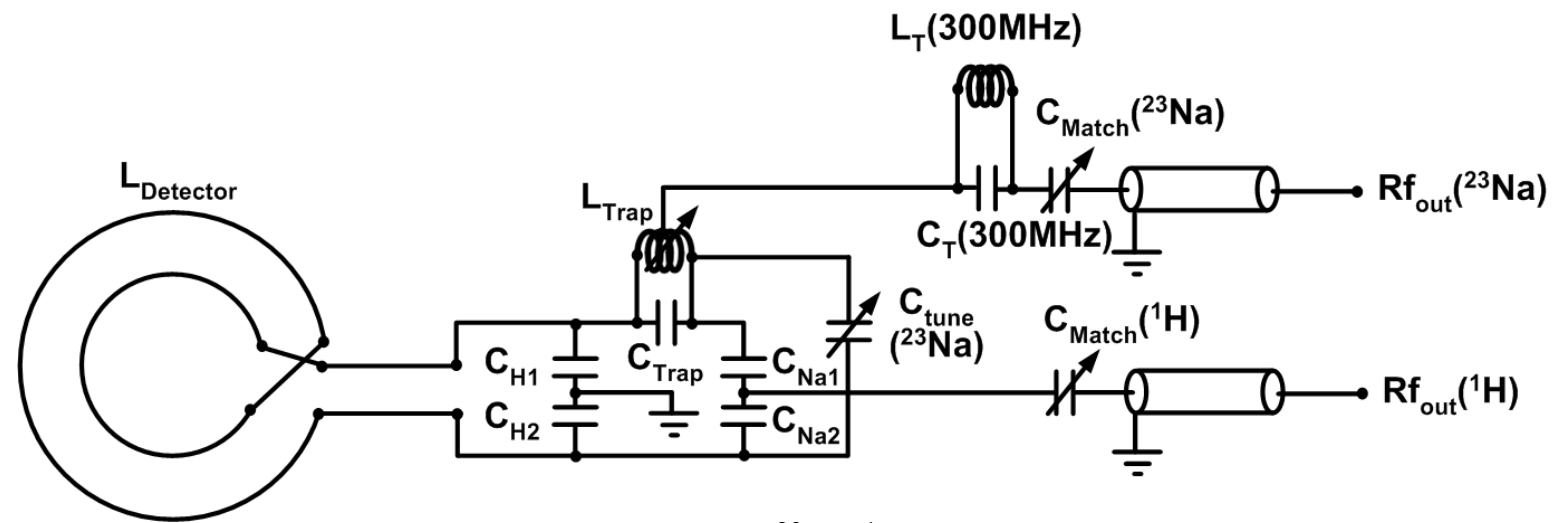

Figure 3: Circuit design of the double-tuned ${ }^{23} \mathrm{Na} /{ }^{1} \mathrm{H}$ transceiver surface coil. $\mathrm{C}_{\mathrm{H} 1}=10 \mathrm{pF}$, $\mathrm{C}_{\mathrm{H} 2}=10 \mathrm{pF}, \mathrm{C}_{\text {Trap }}=4.7 \mathrm{pF}, \mathrm{C}_{\mathrm{Na} 1}=64 \mathrm{pF}, \mathrm{C}_{\mathrm{Na} 2}=30 \mathrm{pF}, \mathrm{C}_{\mathrm{T}}(300 \mathrm{MHz})=3.3 \mathrm{pF}+(0.8-$ $3.2 \mathrm{pF}), \mathrm{C}_{\text {Tune }}\left({ }^{23} \mathrm{Na}\right) / \mathrm{C}_{\text {Match }}\left({ }^{1} \mathrm{H}\right) / \mathrm{C}_{\text {Match }}\left({ }^{23} \mathrm{Na}\right)=0.5-6 \mathrm{pF}$. The trap circuit inductance was made variable for ${ }^{1} \mathrm{H}$ tuning. Also note the ${ }^{1} \mathrm{H}$-blocking circuit which was added into the ${ }^{23} \mathrm{Na}$ matching path.

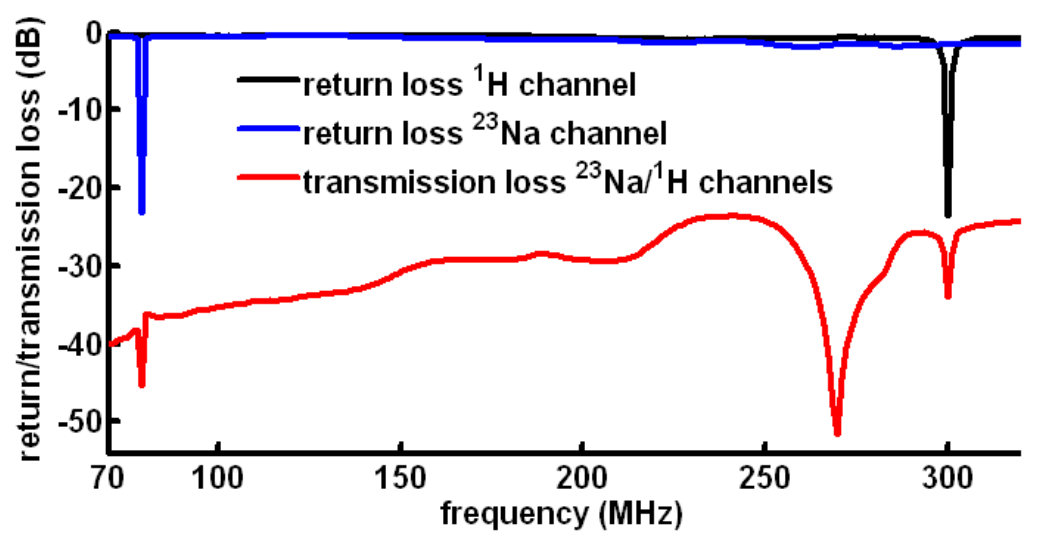

Figure 4: Network analyzer measurements for the newly-developed transceiver surface coil for the ${ }^{23} \mathrm{Na}$ channel connected to port 1 and the ${ }^{1} \mathrm{H}$ channel connected to port $2\left(s_{11^{-}}\right.$and $s_{22}$-measurements for the ${ }^{23} \mathrm{Na}$ and ${ }^{1} \mathrm{H}$ channels, respectively). Note the lack of resonance peak at the undesired resonance frequency, which was characterized by an excellent channel isolation of $<-30 \mathrm{~dB}$ in the $s_{21}$-transmission curve in each case. 

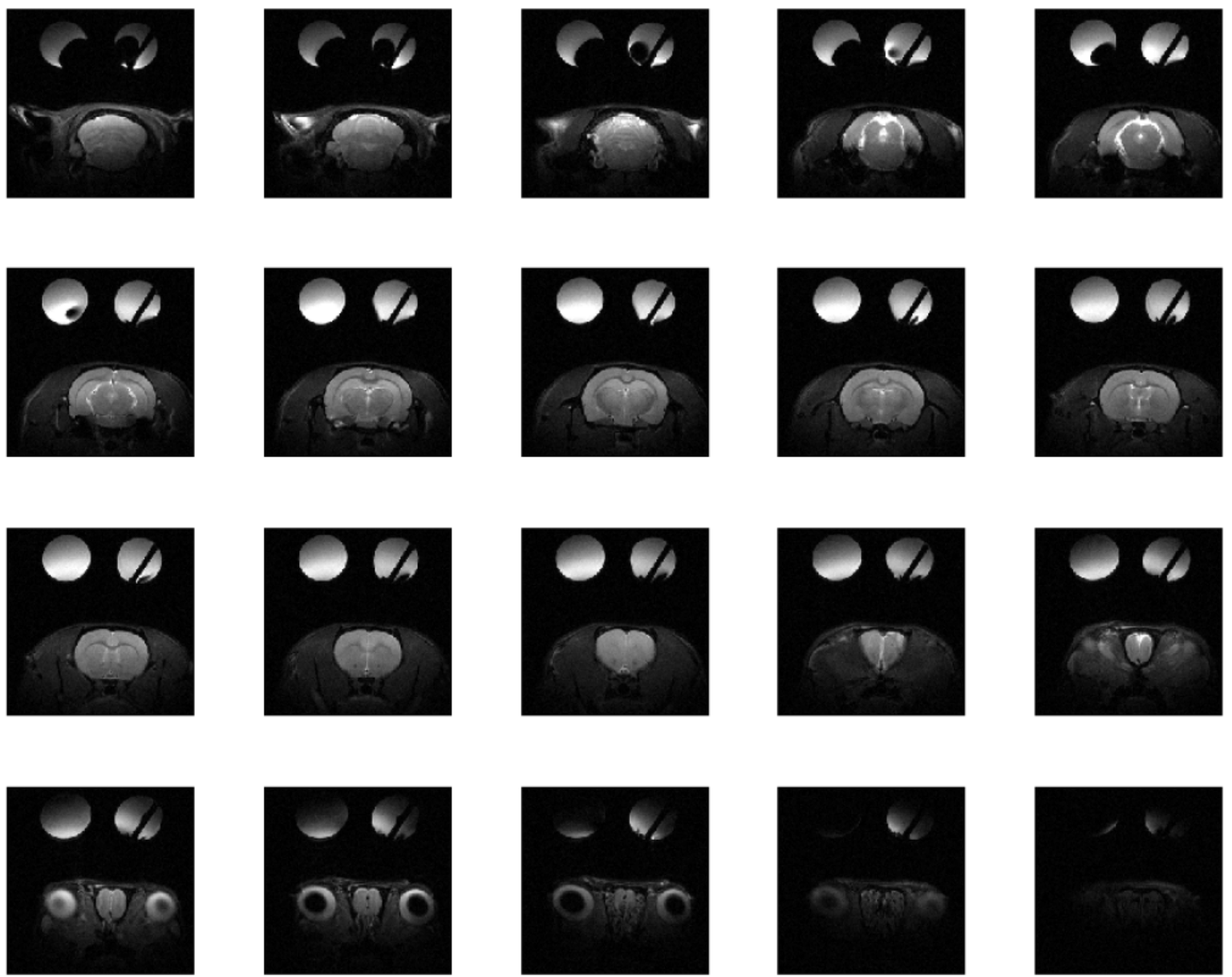

Figure 5: Axial ${ }^{1} \mathrm{H}$ MR images through the rat brain acquired within 5 min $20 \mathrm{~s}$ acquisition time, with $0.2 \times 0.2 \mathrm{~mm}^{2}$ in-plane resolution, and $2 \mathrm{~mm}$ slice thickness. 

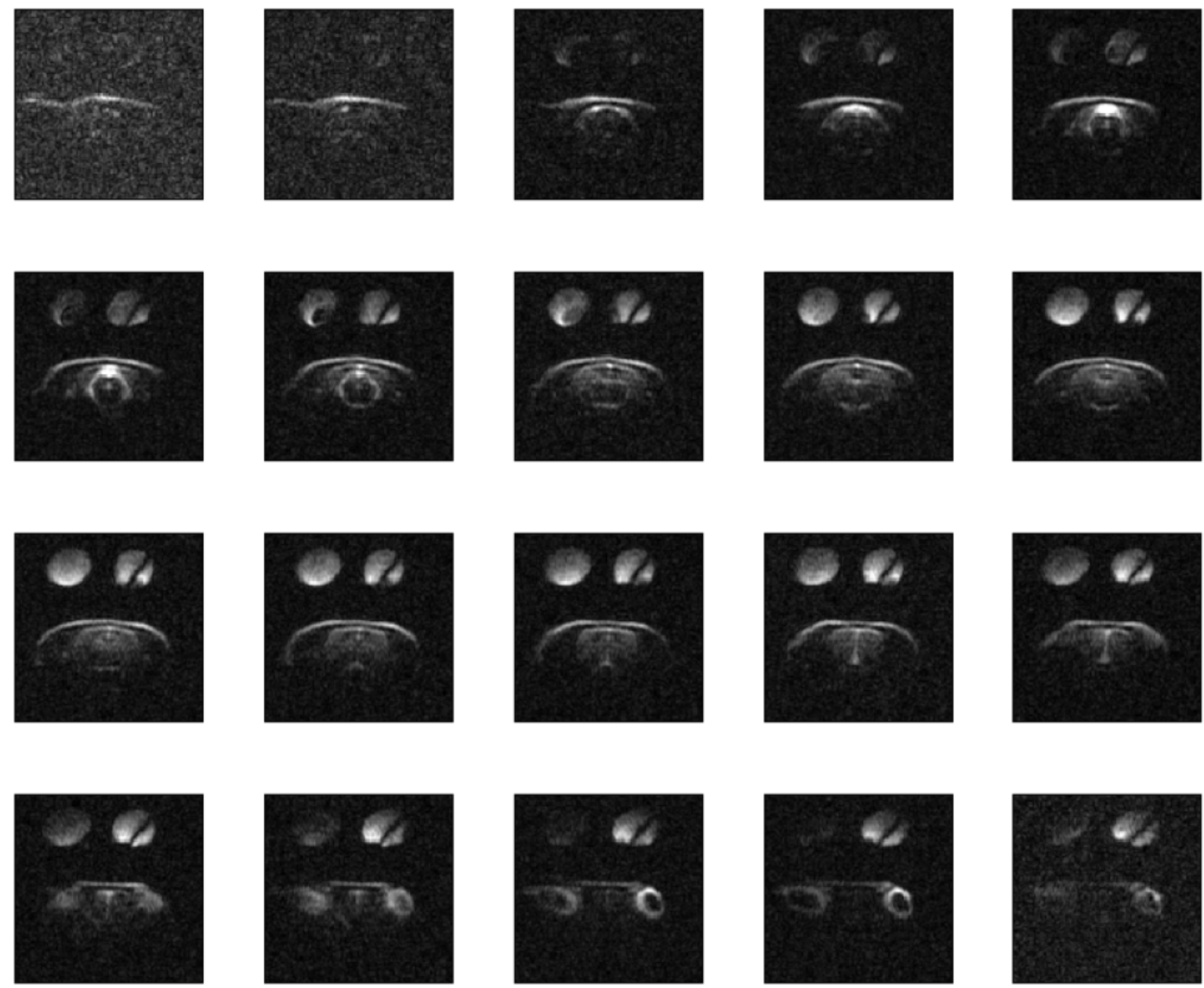

Figure 6: Axial ${ }^{23} \mathrm{Na}$ MR images through the rat brain acquired with 3D FLASH sequence in 40 minutes, with $0.5 \times 0.5 \mathrm{~mm}^{2}$ in-plane resolution, and $2 \mathrm{~mm}$ slice thickness (after 3D zero-filling by factor 2). Two fiducial vials containing gels of known $\mathrm{NaCl}$ concentrations were mounted above the coil for quantification purposes. The fat layer above the brain, which lay in close proximity to the surface detector element, produced a high ${ }^{23} \mathrm{Na}$ signal. 


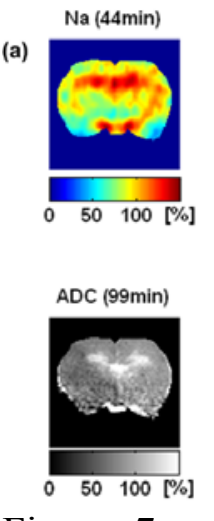

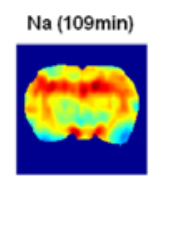

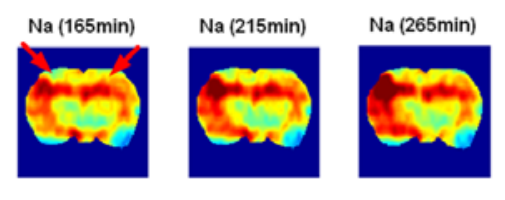

(b)
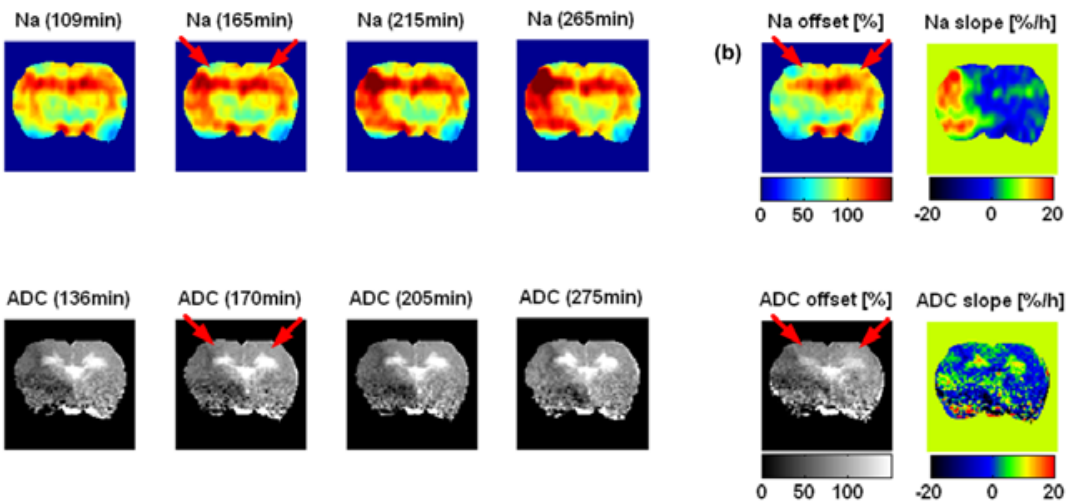

(c)

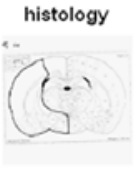

perfusion [\%]

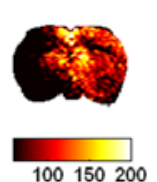

Figure 7: (a) ${ }^{23} \mathrm{Na}$ images and $\mathrm{ADC}$ maps at various time points after stroke, (b) corresponding offset and slope maps, and (c) the infarct outlined on a line diagram as well as the perfusion weighted image of one single slice in a representative stroke rat scaled as percentage of contralateral perfusion in cortex. Note, the different contrast achieved for ischaemic tissue in the slope ${ }^{23} \mathrm{Na}$ (high) and offset ${ }^{23} \mathrm{Na}$ (low) maps, while only marginal changes were observed in ADC slope. With respect to contrast the ADC offset map was similar to each of the single ADC maps. Red arrows in the ADC and ${ }^{23} \mathrm{Na}$ maps indicate the location of penumbra (left arrow) and the corresponding contralateral tissue (right arrow). Notice the differences in ${ }^{23} \mathrm{Na}$ signal as well as ${ }^{23} \mathrm{Na}$ offset in penumbra, while no change was ADC changes were observed in the same region.

\section{References}

[1] S. C. Jones, A. Kharlamov, B. Yanovski, D. K. Kim, K. A. Easley, V. E. Yushmanov, S. K. Ziolko, and F. E. Boada, "Stroke onset time using sodium MRI in rat focal cerebral ischemia," Stroke, vol. 37, pp. 883-8, Mar 2006.

[2] R. P. Kline, E. X. Wu, D. P. Petrylak, M. Szabolcs, P. O. Alderson, M. L. Weisfeldt, P. Cannon, and J. Katz, "Rapid in vivo monitoring of chemotherapeutic response using weighted sodium magnetic resonance imaging," Clin Cancer Res, vol. 6, pp. 2146-56, Jun 2000. 
[3] N. Maril, R. Margalit, J. Mispelter, and H. Degani, "Functional sodium magnetic resonance imaging of the intact rat kidney," Kidney Int, vol. 65, pp. 927-35, Mar 2004.

[4] F. Wetterling, L. Gallagher, I. M. Macrae, S. Junge, and A. J. Fagan, "Regional and temporal variations in tissue sodium concentration during the acute stroke phase," Magnetic Resonance in Medicine, vol. 66, p. in press, 2011.

[5] R. Ouwerkerk, M. A. Jacobs, K. J. Macura, A. C. Wolff, V. Stearns, S. D. Mezban, N. F. Khouri, D. A. Bluemke, and P. A. Bottomley, "Elevated tissue sodium concentration in malignant breast lesions detected with non-invasive (23)Na MRI," Breast Cancer Res Treat, Jan 272007.

[6] K. R. Thulborn, D. Davis, H. Adams, T. Gindin, and J. Zhou, "Quantitative tissue sodium concentration mapping of the growth of focal cerebral tumors with sodium magnetic resonance imaging," Magn Reson Med, vol. 41, pp. 351-9, Feb 1999.

[7] K. R. Thulborn, D. Davis, J. Snyder, H. Yonas, and A. Kassam, "Sodium MR imaging of acute and subacute stroke for assessment of tissue viability," Neuroimaging Clin N Am, vol. 15, pp. 639-53, xi-xii, Aug 2005.

[8] K. R. Thulborn, T. S. Gindin, D. Davis, and P. Erb, "Comprehensive MR imaging protocol for stroke management: tissue sodium concentration as a measure of tissue viability in nonhuman primate studies and in clinical studies," Radiology, vol. 213, pp. 156-66, Oct 1999.

[9] A. Tsang, R. Stobbe, N. Asdaghi, M. S. Hussain, Y. Bhagat, C. Beaulieu, D. Emery, and K. S. Butcher, "Relationship between sodium intensity and perfusion deficits in acute ischemic stroke," Journal of Magnetic Resonance Imaging, vol. 33, pp. 41-47, 2011.

[10] E. A. Mellon, D. T. Pilkinton, C. M. Clark, M. A. Elliott, W. R. Witschey, A. Borthakur, and R. Reddy, "Sodium MR Imaging Detection of Mild Alzheimer Disease: Preliminary Study," American Journal of Neuroradiology, vol. 30, pp. 978-984, May 2009.

[11] M. A. Weber, S. Nielles-Vallespin, H. B. Huttner, J. C. Wohrle, K. Jurkat-Rott, F. Lehmann-Horn, L. R. Schad, H. U. Kauczor, M. Essig, and H. M. Meinck, "Evaluation of patients with paramyotonia at Na-23 MR imaging during coldinduced weakness," Radiology, vol. 240, pp. 489-500, Aug 2006.

[12] A. Borthakur, E. Mellon, S. Niyogi, W. Witschey, J. B. Kneeland, and R. Reddy, "Sodium and T-1 rho MRI for molecular and diagnostic imaging of articular cartilage," Nmr in Biomedicine, vol. 19, pp. 781-821, Nov 2006.

[13] M. Inglese, G. Madelin, N. Oesingmann, J. S. Babb, W. Wu, B. Stoeckel, J. Herbert, and G. Johnson, "Brain tissue sodium concentration in multiple sclerosis: a sodium imaging study at 3 tesla," Brain, vol. 133, pp. 847-857, Mar 2010.

[14] N. Maril, Y. Rosen, G. H. Reynolds, A. Ivanishev, L. Ngo, and R. E. Lenkinski, "Sodium MRI of the human kidney at 3 tesla," Magnetic Resonance in Medicine, vol. 56, pp. 1229-1234, Dec 2006.

[15] V. D. Schepkin, B. D. Ross, T. L. Chenevert, A. Rehemtulla, S. Sharma, M. Kumar, and J. Stojanovska, "Sodium magnetic resonance imaging of chemotherapeutic response in a rat glioma," Magn Reson Med, vol. 53, pp. 85-92, Jan 2005.

[16] F. Wetterling, M. Tabbert, S. Junge, L. Gallagher, I. M. Macrae, and A. J. Fagan, "A double-tuned H-1/Na-23 dual resonator system for tissue sodium concentration measurements in the rat brain via Na-MRI," Physics in Medicine and Biology, vol. 55, pp. 7681-7695, Dec 212010. 
[17] J. D. Christensen, B. J. Barrere, F. E. Boada, J. M. Vevea, and K. R. Thulborn, "Quantitative tissue sodium concentration mapping of normal rat brain," Magn Reson Med, vol. 36, pp. 83-9, Jul 1996.

[18] V. E. Yushmanov, A. Kharlamov, B. Yanovski, G. LaVerde, F. E. Boada, and S. C. Jones, "Inhomogeneous Sodium Accumulation in the Ischemic Core in Rat Focal Cerebral Ischemia by Na-23 MRI," Journal of Magnetic Resonance Imaging, vol. 30, pp. 18-24, Jul 2009.

[19] V. E. Yushmanov, B. Yanovski, A. Kharlamov, G. LaVerde, F. E. Boada, and S. C. Jones, "Sodium Mapping in Focal Cerebral Ischemia in the Rat by Quantitative Na23 MRI," Journal of Magnetic Resonance Imaging, vol. 29, pp. 962-966, Apr 2009.

[20] M. Alecci, S. Romanzetti, J. Kaffanke, A. Celik, H. P. Wegener, and N. J. Shah, "Practical design of a 4 Tesla double-tuned RF surface coil for interleaved $1 \mathrm{H}$ and 23Na MRI of rat brain," J Magn Reson, vol. 181, pp. 203-11, Aug 2006.

[21] G. X. Shen, F. E. Boada, and K. R. Thulborn, "Dual-frequency, dual-quadrature, birdcage RF coil design with identical B1 pattern for sodium and proton imaging of the human brain at 1.5 T," Magn Reson Med, vol. 38, pp. 717-25, Nov 1997.

[22] A. Asfour and V. Auboiroux, "A new dedicated double-tuned (100 MHz-27 MHz) volume RF coil actively-decoupled form a receive-only simple-tuned (27 MHz) coil: application to the MRF experiments of hyperpolarized Xe-129 in the rat brain," 2008 Ieee Instrumentation and Measurement Technology Conference, Vols 1-5, pp. 945-950, 2008.

[23] J. R. Fitzsimmons, H. R. Brooker, and B. Beck, "A Transformer-Coupled DoubleResonant Probe for Nmr Imaging and Spectroscopy," Magnetic Resonance in Medicine, vol. 5, pp. 471-477, Nov 1987.

[24] V. Volotovskyy, B. Tomanek, I. Corbin, R. Buist, U. I. Tuor, and J. Peeling, "Doubly tunable double ring surface coil," Concepts in Magnetic Resonance Part B-Magnetic Resonance Engineering, vol. 17B, pp. 11-16, Apr 2003.

[25] M. D. Schnall, V. H. Subramanian, J. S. Leigh, and B. Chance, "A New DoubleTuned Probe for Concurrent H-1 and P-31 Nmr," Journal of Magnetic Resonance, vol. 65 , pp. 122-129, 1985.

[26] J. Mispelter, M. Lupu, and A. Briguet, NMR Probeheads for Biophysical and biomedical experiments: Theoretical Principles \& Practical Guidelines. London: Imperial College Press, 2006.

[27] R. Bartha, T. Y. Lee, M. J. Hogan, S. Hughes, E. Barberi, N. Rajakumar, and R. S. Menon, "Sodium T2*-weighted MR imaging of acute focal cerebral ischemia in rabbits," Magn Reson Imaging, vol. 22, pp. 983-91, Sep 2004.

[28] S. P. Lin, S. K. Song, J. P. Miller, J. J. Ackerman, and J. J. Neil, "Direct, longitudinal comparison of (1)H and (23) Na MRI after transient focal cerebral ischemia," Stroke, vol. 32, pp. 925-32, Apr 2001.

[29] D. C. Alsop, "The sensitivity of low flip angle RARE imaging," Magnetic Resonance in Medicine, vol. 37, pp. 176-184, Feb 1997.

[30] D. M. Garcia, G. Duhamel, and D. C. Alsop, "Efficiency of inversion pulses for background suppressed arterial spin labeling," Magnetic Resonance in Medicine, vol. 54, pp. 366-372, Aug 2005.

[31] C. Santosh, D. Brennan, C. McCabe, I. M. Macrae, W. M. Holmes, D. I. Graham, L. Gallagher, B. Condon, D. M. Hadley, K. W. Muir, and W. Gsell, "Potential use of oxygen as a metabolic biosensor in combination with T2*-weighted MRI to define the ischemic penumbra," Journal of Cerebral Blood Flow and Metabolism, vol. 28, pp. 1742-1753, Oct 2008. 
[32] V. D. Schepkin, W. W. Brey, P. L. Gor'kov, and S. C. Grant, "Initial in vivo rodent sodium and proton MR imaging at 21.1 T," Magnetic Resonance Imaging, vol. 28, pp. 400-407, Apr 2010.

[33] M. Augath, P. Heiler, S. Kirsch, and L. R. Schad, "In vivo K-39, Na-23 and H-1 MR imaging using a triple resonant RF coil setup," Journal of Magnetic Resonance, vol. 200, pp. 134-136, Sep 2009.

[34] A. M. Nagel, F. B. Laun, M. A. Weber, C. Matthies, W. Semmler, and L. R. Schad, "Sodium MRI Using a Density-Adapted 3D Radial Acquisition Technique," Magnetic Resonance in Medicine, vol. 62, pp. 1565-1573, Dec 2009. 